\title{
Analysis on the Role and Functions of Teachers, Teaching Materials and Learners in the Multimedia-aided English Classroom-Based on the Study of Linfen No.1 Senior School
}

\author{
Le Zhang \\ Shanxi Normal University, Linfen, China
}

\begin{abstract}
Recently, with the development of network and technologies, the traditional teacher-centered mode is gradually losing its main status. Multimedia-assisted foreign language teaching is becoming the most popular way of teaching. At present, computer based multimedia is broadly used in classrooms. Multimedia-aided English teaching can introduce video, figure, and text into teaching practice, and improve English teaching efficiency. Teachers, teaching materials and learners, as the three main elements in English teaching, play an essential part in classroom. Although relevant surveys have been done investigating English classroom under the conventional educational mode, very few people have thought the change of the three elements more specific. Therefore, the paper talks about the difference between the conventional educational model and multimedia-aided teaching method in English classroom. The author takes the teachers and students in Linfen NO.1 senior school as the research object, aiming to study the role and the interrelationship of the three. Through interviews, classroom observation and questionnaire, the thesis concisely summarizes the role and functions of the three elements in Linfen NO.1 senior school. It is a rational analysis and summary of multimedia-assisted English teaching theoretically and practically. Thus it will be helpful for the improvement of English teaching effect.
\end{abstract}

Index Terms - multimedia-assisted teaching, role and functions of teachers and learners, senior English class

\section{INTRODUCTION}

\section{A. Background of the Study}

It has undoubtedly proved that advanced technology is a most forceful tool conducing development and reforms in the human society and the network technology is such a reforming factor in the current world. Since the updated reform of curriculum with modern educational technology, the traditional role of teachers and learners has been changing bit by bit, as same as the conventional mode of foreign language teaching. Hence, more and more researchers have been facilitating exploration of new methods and new mode of classroom teaching, trying to have a new educational revolution in China. Then from the 1990s, the practical application of multimedia technology became one of the characteristics in the computer in China. Therefore the application of multimedia is the automatic result of the advancement of modern science and technology, and has become as an essential means for English teaching. In recent decades, multimedia-aided English teaching is presently becoming very common and popular with many learners and teachers. Facing the new change, people have also become conscious of the importance of multimedia in English teaching and learning. And many researchers point out that the role and functions of teachers, teaching materials and learners also changed to some extent. So it is essential for us to analyze the change of teachers and students in the multimedia-aided English teaching. The survey has a significant influence on improving our teaching effect.

\section{B. Purpose and Significance of the Study}

Network is closely related to English teaching. Computer can be used as a tool for students and teachers to communicate in class and to stimulate the teaching effect. The paper is going to point out the major difference between traditional English educational pattern and the new multimedia-aided English teaching and learning mode. Meanwhile, the author is concentrated on studying the role and functions of teachers, teaching materials and students with the help of computers. The paper is meant to study the interrelationship of the three elements, so as to stimulating students' interest in learning and improving the quality of teaching effectively.

By a review of related theories, the author designs questionnaires for the purpose of the actual performance of media in English teaching and learning. Meanwhile, the author tries to explore the real situation of multimedia application in Linfen NO.1 senior school, aiming at finding out problems in the process of multimedia-aided instruction with the basis of relative theories on multimedia-assisted instruction. It is hoped that the research could provide us some ideas about current multimedia practices and the ideal state. 


\section{LITERATURE REVIEW}

The relevant researches on multimedia-aided instruction have a long history both abroad and at home, in which the former is longer than the latter, and which will be represented in this section.

\section{A. Research on Multimedia-assisted Instruction Abroad}

Multimedia Technology, also called media. Marshal states that "media is information". Gayeski (1993) regards multimedia as "a kind of computer driven interactive communication system which produce, reserve, send, and retrieve textual, pictural, and acoustic networks of information." (p. 4). Then a generic term "multimedia" refers to the continuing or by synchronous application of all kinds of media in a given presentation or self-learning program (Sharon E, 2005, p.14). In short, multimedia technology is the carrier which carries information such as tapes, films, books, computers, tapes, disks, televisions and so on.

The relevant researches abroad initiated since the 1960s. At that time computer technology developed quickly. In the 1980s and the 1990s, scholars aboard have been analyzing in such areas as whether multimedia can facilitate teaching; what kind of effect it can produce; how we can make the most of it.

In the early of 1980's, experts come to be interested in multimedia-aided instruction research. Some materials introduce the computers' usage in classrooms such as Hainline, 1987, New Developments in Computer-Assisted Language Learning; Higgins \& Johns, 1984, Computer in Language Learning. Higgins and Johns (1984) generally described computer technology and the application of computer technology in classroom. Generally speaking, the researches on multimedia-aided instruction mainly focus on the development of individual processes, strategies and competencies, using measures such as motivational surveys, observations, recordings of keystrokes, and think- aloud protocols.

In the 1990s, Kozma (1991) explained his opinion that the students and media actively collaborated to construct their knowledge, which was different from those who held multimedia were only the transferring devices of teaching content. Then, Norman analyzed the interrelationship between the "carrier" and "structure" characters and the instructional aims (Dai, 2005); Monaghan and Stenning discussed whether the student differences exist in the teaching process of solving problems by learning multimedia(Dai, 2005); and Pane, Corbett and Jone implemented the comparative experimental researches between text descriptive media and animation media( Dai, 2005).

In short, with the previous development of multimedia technology, researches have made great success based on the continuous improvement of technology and educational theories abroad. Besides, these researches play an important part in applying multimedia to foreign language teaching and learning, and they are the guidance of Chinese multimedia-aided instruction researches.

\section{B. Research on Multimedia-assisted Instruction at Home}

In China, the application of computer in education is much later than those abroad. Since 1999, multimedia technology is applied in college English teaching (Cai, 2003). It developed rapidly, and the relevant research results reflect the real features and problems of education. Recently, the researches on multimedia-aided instruction mainly place the emphasis on the following aspects:

Some scholars emphasize the significance of integration the multimedia technology into English learning and teaching, for example, An Jing (2004), Wu Min (1999). All of them hold that the integration of multimedia technology does promote the language learning process effectively and help learners to raise their overall ability to apply English.

Some give a statistical analysis and literature review of the papers concerning research on multimedia-assisted foreign language teaching in China published in 8 major linguistic journals during 1995-2006, which point out that the research methods are mainly not empirical, such as $\mathrm{Na}$ Min and so forth.

Some discuss the multimedia-assisted English learning and teaching under the guidance of the Constructivist theory, such as Wang Xiangling \& Ning Chunyan (2002).

Nearly all the experts agree that multimedia technology is a useful method to assist teaching and it can promote the teaching effect. They realize the advantages and disadvantages as well and some of them have put forward the improving suggestions.

\section{Methodology}

\section{A. Objects and Subjects}

\section{Objects}

The study aims at studying the role and functions of teachers, teaching materials and learners in the multimedia-aided teaching, compared with the traditional teaching mode. More specifically, there are three research questions:

(1) What are the role and functions of teachers in the multimedia-assisted English teaching mode?

(2) What are the role and functions of teaching materials in the multimedia-assisted English teaching mode?

(3) What are the role and functions of learners in the multimedia-assisted English teaching mode?

\section{Subjects}

The author chooses 5teachers and 2 classes in Grade 1 in Linfen NO.1 senior school as the research subjects. The five 
teachers all have more than 10 years teaching experience. The average size of each class varies from 55 to 65 students, and their age range from 16 to 18. Most of them have learned English since Grade 3 of primary school and some of them have learned English for 8 years. So they are treated as intermediate English learners.

TABLE 1

GENDER AND AGE CONDITIONS OF THE SUBJECTS

\begin{tabular}{|l|l|l|l|}
\multicolumn{4}{|c|}{ GENDER AND AGE CONDITIONS OF THE SUBJECTS } \\
\hline & Females & Males & Average age \\
\hline English teachers(5) & 3 & 2 & 35 \\
\hline Students(80) & 32 & 48 & 17 \\
\hline
\end{tabular}

\section{B. Instruments}

The author adopts classroom observation, after-class interview, questionnaire analysis and literature study. The author sorts, analyzes and classifies the materials in order to make it more systematic.

\section{Classroom Observation}

Classroom observation is a formal or informal observation of teaching while it is applied in a classroom or other learning environment. In the research, the author observes about 80 students and does class record accordingly. During the process of observation, the author carefully observes the change of teachers and learners.

\section{After-class Interview}

In the study, the author spends free time in having some interviews for teachers and students. In this way, the author can better grasp the learning effect of students. And in the process of interviewing, the author tries to create an active atmosphere as much as possible. As a result, the author can gain unexpected information.

\section{Questionnaire Analysis}

In the study, the author designs the questionnaire about the influence of media to students in English classroom and chooses 80 students from Class 387, and Class 388 of Linfen NO.1 senior school to conduct questionnaire surveys.

The questionnaire is made up of 10 questions and all of them are multiple-choice. They are easier to answer and will not take too much time.

\section{Literature Study}

Mainly according to the purpose and the content of the study, the theory of the paperis based on the books, the library, the internet and other resources.

\section{Teachers, Teaching Materials And Learners under Multimedia-Aided Teaching}

\section{A. The Role and Functions of Teachers under Multimedia-aided Teaching}

\section{Previous Researches on Conventional Teacher-centered Teaching Model}

Zhang Haitao (2001) points out that some schools still follow the model of "reviewing the former lesson---introducing the new lesson---explaining the new lesson---strengthening the new lesson---assigning homework" as it did decades ago. The common teaching pattern is reading, questioning, explanation and grammar exercise. Students depend too much on the teacher and lack a sense of responsibility for their own learning (Shu, 1992, p.20). The conventional English teaching approach still involves teacher's knowledge conveyance but there are few interaction between the teacher and the learners. Following the kind of teaching model, the teacher becomes the center and the core of the teaching activities. In other words, the teacher is the controller of the teaching process and the transmitter of the knowledge, while the learner is only the receiver of the knowledge and information, the blackboard, the chalk and the textbook are the main teaching tools. In the teacher-centered teaching pattern, if we compare the whole teaching course to the process of a play, the teacher can be identified as the director while the learners can be regarded as silent target audience.

By studying previous researches, it can be discovered the teacher-centered teaching pattern exists the following characteristics:

(1) There is mainly one-way conveyance in the teaching model. That is, just from the teacher to the learner.

(2)The teacher takes the grammar-translation method as the main approach when teaching.

(3) The main teaching materials are the books and textbooks. The teacher plans teaching activities based on the points of textbook.

(4) The students are the passive recipient of the language. They spend most of time in writing down the notes and listening to their teachers in the language teaching process.

(5) The learners only learn knowledge in the classroom, they sit in their fixed seats while the teacher stands in the front, and the books, blackboard and chalks are the major teaching instruments.

\section{The Role and Functions of Teachers under Multimedia-aided Teaching}

The traditional teacher-centered teaching pattern can be taken as a practical and effective teaching model in the last decades. However, as information technology and society develop rapidly in recent years, the conventional teacher-centered teaching model is already out of fashion. With more and more attention is paid to the learners' initiative, the shortcomings of the teacher-centered teaching pattern emerge. It is important and necessary to reform the long-term teacher-centered English teaching way, for it cannot apply for the current situation any more. 
Due to the distinctive features of multimedia technology, it is imperative for the teacher to take full advantage of computer and play diverse and multiple roles in line with different teaching requirements.

(1) The teacher can play the role as a planner when he makes preparations and plans for the whole teaching and learning course before class.

(2) The teacher can play the role as an organizer when he asks the learners to do some learning activities such as doing a discussion in the classroom.

(3) The teacher can play the role as a participant when he serves as an equal to participate in the activities with the learners.

(4) The teacher can play the role as a supervisor when he examines the students' homework and other learning activities.

(5) The teacher can play the role as an adviser when he wants to assess the students' learning result and offer feedback.

(6) The teacher can play the role as a source when some students ask him for some difficult questions.

(7) The teacher can play the role as a promoter when he wants to inspire the students' learning interests and performance.

TABLE 2

RESUlTS OF TEACHERS' OPINIONS ABOUT THE ROLE AND FunCTIONS OF TEACHERS UNDER MULTIMEDIA-AIDED TEACHING (1=strongly disagree; $2=$ disagree; $3=$ undecided; $4=$ agree; $5=$ strongly agree)

\begin{tabular}{|c|c|c|c|c|c|c|c|c|c|c|}
\hline \multicolumn{11}{|l|}{ Teachers' Opinions } \\
\hline \multirow[t]{2}{*}{ Questions } & \multicolumn{5}{|c|}{ Theoretical Agree } & \multicolumn{5}{|c|}{ Practical agree } \\
\hline & 1 & 2 & 3 & 4 & 5 & 1 & 2 & 3 & 4 & 5 \\
\hline 1 A planner role & $0 \%$ & $6 \%$ & $4 \%$ & $44 \%$ & $46 \%$ & $0 \%$ & $4 \%$ & $30 \%$ & $26 \%$ & $40 \%$ \\
\hline 2 An organizer role & $2 \%$ & $0 \%$ & $0 \%$ & $35 \%$ & $63 \%$ & $0 \%$ & $0 \%$ & $13 \%$ & $55 \%$ & $32 \%$ \\
\hline 3 A participant role & $0 \%$ & $7 \%$ & $8 \%$ & $20 \%$ & $65 \%$ & $0 \%$ & $5 \%$ & $37 \%$ & $30 \%$ & $28 \%$ \\
\hline 4 A supervisor role & $0 \%$ & $2 \%$ & $4 \%$ & $25 \%$ & $59 \%$ & $0 \%$ & $3 \%$ & $29 \%$ & $40 \%$ & $28 \%$ \\
\hline 5 An adviser role & $0 \%$ & $0 \%$ & $0 \%$ & $33 \%$ & $67 \%$ & $0 \%$ & $0 \%$ & $15 \%$ & $38 \%$ & $47 \%$ \\
\hline 6 Asource role & $0 \%$ & $0 \%$ & $0 \%$ & $29 \%$ & $71 \%$ & $0 \%$ & $3 \%$ & $19 \%$ & $27 \%$ & $51 \%$ \\
\hline 7 A promoter role & $7 \%$ & $0 \%$ & $5 \%$ & $18 \%$ & $70 \%$ & $0 \%$ & $3 \%$ & $25 \%$ & $42 \%$ & $30 \%$ \\
\hline
\end{tabular}

The author also has some interviews with the 5 English teachers in Linfen NO.1 senior school, which the main questions including:

(1) Do you often use multimedia in the process of English teaching?

(2) What do you think are the major difficulties and problems in multimedia assisted foreign language teaching?

(3) Compared with the traditional teaching pattern, what are the advantages and disadvantages of multimedia assisted English teaching?

(4) Are you satisfied with the courseware you are using? Do you have any suggestions on how to improve the course ware?

(5) Do you think computer assisted foreign language teaching needs to be further improved teachers, learning software, activities and so forth?

(6) In order to make use of computer assisted English teaching, do you have any suggestions?

By answering those questions, the five teachers all hold a positive attitude to multimedia. They think with the help of the multimedia, students' interest in learning is stimulated better and the teaching effect is improved effectively.

By serious empirical researches and data analysis in Linfen NO.1 senior school, the author comes to a conclusion about the role and functions of teachers in the multimedia-assisted English environment. And based on the analysis, we can say that, to some extent, the seven roles of the teacher in the multimedia-aided English classroom are reasonable and meaningful.

\section{B. The Role and Functions of Teaching Materials under Multimedia-aided Teaching}

\section{Characteristics of the Evolution of Teaching Materials}

As one of the elements in language teaching, teaching materials play an important part. With the social-political transitions in China and the world, the evolution of teaching materials has been changing with the following characteristics:

(1) A transformation from teacher-centered instruction to student-centered exploration;

(2) A transformation from the propaganda of simple language knowledge to the training of language skills and communicative competence.

(3) A transformation from learners passively receiving knowledge to learners working independently and cooperatively.

\section{The Role and Functions of Teaching Materials under Multimedia-aided Teaching}

With the advancement of technology, teaching materials also become diversified. In the past, textbooks occupy the leading role in the process of English teaching. The teacher and learner depend on the textbooks to finish the class. And the design of teaching materials is dull, which can neither stimulate learners' learning interest nor improve teaching efficiency to some extent. 
Nowadays, with the help of network and information technology, the design of teaching materials presents some new characteristics such as diversity, vitality and interactivity and so forth. At the same time, multimedia has becoming an indispensable tool in the process of English teaching. Combining textbooks and multimedia during the teaching, both the teacher and the students can enjoy the learning atmosphere better.

\section{The Role and Functions of Learners under Multimedia-aided Teaching}

\section{Previous Researches on the Role and Functions of Learners}

Generally speaking, the traditional teaching pattern can be described as the following method "Centering in teaching, teachers teach knowledge by taking explaining, writing on blackboard and using all kinds of teaching materials as teaching instruments and methods, while students just passively receive what teachers teach." (Shu, 2004) In the teaching pattern, the teacher is initiative knowledge imposers while the student is passive receiver of external stimulation and objects of knowledge instillation. Materials are content being instilled by the teacher and learning media are the means for the teacher to instill knowledge to learners.

\section{The Role and Functions of Learners under Multimedia-aided Teaching}

With the increasing use of multimedia in English teaching, it is obviously becoming more and more convenient. Meanwhile, it changed the traditional single teaching mode completely. Under the present situation, it is necessary and important to reorient the role and functions of learners. Under the environment of multimedia-aided English teaching, the student will change their role from a passive recipient to an independent learner. Multimedia technology can provide students with a variety of sound information, which is conducive to improve the students' listening ability and is conducive to learn the standard pronunciation and intonation. Besides, students can use the multimedia courseware to learn by themselves and by learning, they can obtain a wealth of language knowledge and communicate in English. In the process of learning, students can control the process and tasks of learning, so as to realize the autonomy and exploration of the learning process.

In short, in the process of multimedia-aided foreign language teaching, the role of students should be located as independent and automatic learners, the center of teaching activities, the participants of communicative activities, and the sharing of information resources.

Through some interviews and questionnaires to 80 students in Linfen NO. 1 senior school, the author draws some conclusions which presented as follows:

TABLE 3

LEARNER'S COMPUTER EXPERIENCE

\begin{tabular}{|l|l|}
\hline Item 1 I began to use computer in & \\
\hline Preschool (\%) & 0 \\
\hline Primary school (\%) & 22.54 \\
\hline Junior middle school (\%) & 45.25 \\
\hline Senior middle school (\%) & 32.21 \\
\hline Item 2 I can skillfully use & \\
\hline Email (\%) & 96.5 \\
\hline Web browser (\%) & 95 \\
\hline Chat room (\%) & 98 \\
\hline Image editing (\%) & 54.21 \\
\hline Item 3 I can surf on the internet conveniently. & \\
\hline Yes (\%) & 97,45 \\
\hline No (\%) & 2.55 \\
\hline
\end{tabular}

From Item1and Item 2, we can know that the computer literacy among students is more than satisfactory. Most students began to use a computer in the middle school (Item1); almost all of the students can make good use of email, chat room as well as web browser.

TABLE 4

A SURVEY ON LEARNERS' APPLICATION OF INTERNET IN THE PROCESS OF LEARNING ENGLISH

\begin{tabular}{|l|l|}
\hline Item 3 I use the Internet and courseware to learn English & \\
\hline Every day (\%) & 2.35 \\
\hline More than three times a week (\%) & 16.38 \\
\hline Two to three times a week (\%) & 20.35 \\
\hline Once a week (\%) & 10.32 \\
\hline Once two weeks (\%) & 2.34 \\
\hline Once a month (\%) & 2.56 \\
\hline Only before examinations (\%) & 43.27 \\
\hline Never (\%) & 2.43 \\
\hline Item4 I use the Internet and courseware to learn English for each time. & \\
\hline Two hours and more (\%) & 8,63 \\
\hline Less than two hours (\%) & 88,21 \\
\hline Zero hours (\%) & 3.16 \\
\hline
\end{tabular}

From Item 3 and Item 4, we can know that the use of internet in the process of learning English vary greatly among 
students. Roughly speaking, half of them use a computer to learn English after class, a portion of $43.27 \%$ use it only as a kind of preparation for exams; $2.35 \%$ use it every day and $2.43 \%$ never use it except in class.

Besides, the author also spends much time in interviewing some students after class. The students are encouraged to tell the truth during the interview. And the results and analysis of the interview are showed as follows:

Question 1: Have you ever heard the learner-centered teaching model? How do you think about it?

Interviewee 4: "Yes. I have heard the new term. As for me, it's a good way to help us to learn English. Under the student-centered pattern, the student will have more opportunities to speak out in the class and the students' learning interest can be inspired better.

Question 2: What are the problems you are faced with in English learning?

Interviewee 3: "I find I am not so interested in English learning and the English class is boring. We are occupied by watching what have been unfolded in the screen and by listening what the teachers say. Our listening and speaking abilities are still at a lower level."

Question 3: What kind of roles should a teacher play in the process of teaching? What are your opinions to the development of multimedia-aided language learning?

Interviewee 4: "I think in the future all the English class will adopt the way of multimedia assisted language learning. It will make the learning more interesting. I am happy to be taught in a computer classroom, but I don't think my English teacher can make good use of computer. As for the teacher's role, teachers should act like a director or organizer or maybe promoter in students' learning."

Question 4: In order to improve teaching quality, what are your suggestions?

Interviewee1: "With the development of multimedia computer, the teaching focus should be transferred from the teacher to the learners. So a new learner-centered teaching pattern should be established. We students should be encouraged to learn English on our own. And learners shouldn't be the knowledge recipients but the pioneers in learning activities."

\section{CONCLUSIONS}

\section{A. Findings of the Research}

The paper takes Linfen NO.1 senior school as an example, discussing the role and functions of teachers, teaching materials and learners in the multimedia-aided English classroom and put forward some effective suggestions. After classroom observation, questionnaire and interview, the author gets the main findings about the reorientation of teachers, teaching materials and learners as follows:

(1) In traditional foreign language teaching, the teacher is the controller of the class and the teacher-centered teaching mode is applied to many schools. In multimedia computer assisted language learning environment, the role of teacher's has changed a lot. The teacher can play the role as a planner to plan the whole teaching process; as a supervisor to supervise the teaching activities; as an organizer to organize the learning activities; as a prompter to encourage the student to participate in various activities; as a participant to take part in the learning as an equal; as an adviser to offer the feedback, and as a source to provide various information.

(2) In the past, the main teaching materials are textbooks. However, in the multimedia-aided English teaching, textbooks are not the single source of knowledge any more. With the help of computers, the design of teaching materials becoming more and more popular with students.

(3) Learners just passively receive what teachers teach in the traditional teacher-centered teaching mode. However, under the multimedia-assisted environment, the teaching pattern shifts from teacher-centered to learner-centered. That is, learners become the center of teaching activities and they can be seen as independent and automatic learners.

\section{B. Limitations of the Study}

Though the study has been carefully and seriously conducted and designed, it still has some limitations that should be paid more attention in future study. Firstly, the data collected is limited in the study. Only 5 teachers and 2 classes are chosen as observed subjects, and the teachers and learners all come from the same school. Secondly, the obtained data has not been analyzed deeply yet. Some conclusions derived from the author's observation and experience, so the paper still needs further research and investigation.

\section{Suggestions for Further Research}

In recent years, the application of multimedia technology into foreign language teaching process has become a more and more popular practice in China. Besides, most high schools and senior schools have joined in the reform. Thus, the author's advice for further research is that people do experiments in senior schools and discover ways to balance the teacher, the teaching materials and the student so that multimedia-assisted language teaching may greatly improve the quality of foreign language teaching and applying to people of different ages.

\section{REFERENCES}

[1] An Jing. (2004). A Study on the Effectiveness of Improving English Learning and Using Ability under CALL. Computer-assisted Foreign Language Education, 4, 63-66. 
[2] Cai Jigang. \& Wu Shixing. (2003). The introduction of multimedia network technology and the reform of the traditional teaching model. Foreign Language World, 6, 2-7.

[3] Dai Jun. (2005). A Study on the Effectiveness of Multimedia Assisted Instruction in Foreign Countries. Beijing: Comparative Education Review.

[4] Gayeski, D. M. (Ed.). (1993). Multimedia for learning: Development, application, evaluation. New Jersey: Educational Technology Publications.

[5] Hainline, D. (1987). New Developments in Computer-assisted Instruction. New York: Nichols Publishing Company.

[6] Higgins, J. \& Johns, T. (1984). Computer in Language Learning. London and Glasgow: Collins ELT.

[7] Kozma, R. B. \& Johnston, J. (1991). The technological revolution comes to the classroom. Change, 23, 10-23.

[8] Shu Baimei. (1992). Teaching Intensive Reading within A Communicative Framework. Beijing: Foreign Language Teaching and Education Press.

[9] Shu Baimei. (2005). Outline of Foreign Language Education. Wuhan: Huazhong Normal University Press.

[10] Smaldino, S.E. \& Russell, J.D. \& Heinich, R \& Molenda, M. (2005). Instructional Technology and Media for Learning. Beijing: Higher Education Press.

[11] Wang Xiangling. \& Ning Chunyan. (2002). Research on Network English Teaching Based on Constructivism. Computer-assisted Foreign Language Education, 2, 20-23.

[12] Wu Min. (1999). The Application of Multimedia and Network Technology in English Teaching. Education \& Modernization, 4 , 27-30.

[13] Zhang Haitao. (2001). A Research to the Teaching Mode of Large Classroom in Public English. Foreign Language Learning Theory and Practice, 4, 3-9.

Le Zhang was born in Linfen, China in 1994. She is studying for a master's degree in linguistics from Shanxi Normal University, China.

She is currently a postgraduate in the College of Foreign Languages, Shanxi Normal University, Linfen, China. Her research interests include Foreign Language Teaching and Learning and Pragmatics.

Le Zhang is now an external teacher of the College of communication in Shanxi Normal University. 